\title{
Research concerning the springback prediction in the bending operations
}

\author{
Florica Mioara Șerban ${ }^{1, a}$, Nicolae Bâlc ${ }^{1}$, Gheorghe Achimaș ${ }^{1}$, \\ Ciprian Cristea ${ }^{2}$ \\ ${ }^{1}$ Technical University of Cluj-Napoca, Department of Manufacturing Engineering, Bd. Muncii 103-
\[ 105,400641 \text { Cluj-Napoca, Romania } \] \\ ${ }^{2}$ Technical University of Cluj-Napoca, Department of Electrical Machines and Drives, G. Baritiu \\ street 26-28, 400027, Cluj-Napoca, Romania
}

aemail: Florica.Groze@tcm.utcluj.ro

Keywords: Bending, Springback, Finite element simulation, Artificial neural networks, Adaptive neuro-fuzzy inference system

\begin{abstract}
Nowadays firms are required to obtain high quality products in order to increase their competitiveness. The time required to obtain a new product is also essential to fight the concurrence. For manufacturers of bent parts, accurate prediction of the springback is very important. Therefore, this paper investigates the applicability of artificial neural networks (ANN) and adaptive neuro-fuzzy inference system (ANFIS) to predict the springback in the free cylindrical bending process of metallic sheets. The finite element method (FEM) was used to simulate the springback in the free cylindrical bending process and the results were used as training data for ANN and ANFIS. The finite element results were validated by comparison with experimental data. Statistic criteria were used to evaluate the performance of the developed ANN and ANFIS models. It was found that the predictions are in good agreement with the FEM data.
\end{abstract}

\section{Introduction}

Sheet metal bending operation is one of the most frequently used forming procedures in the production of metallic parts. Many of the goods around us are obtained by various bending operations. One of the factors that affect the quality of bent parts is springback. Springback can be defined as an elastically-driven change of shape of a deformed product which takes place during removal of external loads. It is a complex physical phenomenon which is mainly governed by the stress state obtained at the end of a deformation [1]. The amount of springback depends on many factors including the material properties (Young's modulus, Poisson's ratio, strength coefficient, yield stress, strain hardening and anisotropy coefficients), bending operation (tooling geometry, pad force, clearance, initial bend angle and bend radius, contact friction condition etc). In order to obtain parts at required dimensions and tolerance limit is very important to determine as accurate as possible the springback amount.

Many research conducted in the past investigated the springback behavior in different bending operation using numerical and experimental methods. A finite element program was used in [2] to analyze the effect of tool geometry and blank holder force on the final shape after springback in the $\mathrm{U}$ bending process of sheet metals. In paper [3] the authors investigated numerically and experimentally the variation of springback in $U$ bending due to material anisotropy. The effect of tool temperature on the reduction of springback amount of aluminum 1050 sheet was investigated in [4]. Springback values for different bending angles of aluminum and stainless steel specimens were obtained in [5] and converted into graphics for the air bending process. The springback characteristics in plain strain $U$ bending process by thermo-elastoplastic finite element analysis (FEA) was studied in [6]. In paper [7] the authors carried out a finite-element simulation of springback in sheet metal forming using local interpolation for tool surfaces. In [8] an elasto-plastic analysis of sheet metal bending process was carried out using FEM to predict the springback. In paper [9] the authors carried out FEA to see the stress distribution and predict the springback in free 
bending and square cup deep drawing for stainless steel and the results were compared with the experimental data. Experimental observations and finite element method were performed in [10] to investigate the bending and springback phenomena of a stainless-steel clad aluminum sheet in $\mathrm{V}$ shaped air bending. In paper [11] the authors developed a model to predict the springback in $U$ shaped channels bent under plane-strain conditions. An adaptive multiple scale meshless method was developed by authors [12] to predict the amount of springback which occurs after unloading in sheet metal forming. The effect of the material-hardening mode on the springback simulation accuracy of $\mathrm{V}$ free bending was studied in [13]. The springback was analyzed by using a selfdeveloped 2D elasto-plastic finite element program. A linear-hardening model and an elasto-plasic power-exponent hardening model were adopted in their study. Authors [14] proposed a model which takes into account the elastic modulus evolution with plastic prestrain and the unloading stress to predict the springback amount.

The drawback of the analytical models is that they are formulated with significant simplifications of process conditions and material properties which can considerably affect the accuracy of the results. Artificial intelligence techniques such as ANN and ANFIS can be developed using the experimental data without having to do any simplifications. Instead, sufficient input-output data sets for training and testing are required. In the last years these techniques have been used in various engineering fields including sheet metal forming. In paper [15] the authors proposed a fuzzy learning back-propagation algorithm to predict the springback in V-die bending process using the data generated based on experimental observations. The performance of the model in training and testing is compared with those of the constant learning rate backpropagation and the variable learning rate back-propagation algorithms. The influence of process variables (hole type, number of holes, die radius and pad force) on springback in wipe bending for perforated components was investigated in [16] using experiments, finite element method and neural networks. The results of the finite element model were compared with experiments and used as the training data for two artificial neural networks. In paper [17] the authors developed a technique based on artificial neural network and a genetic algorithm to solve the problem of springback in the $U$ shaped bending. The response-surface model was employed in [18] as a fast analysis tool to surrogate the timeconsuming finite-element procedure in the iterations of the multi-objective genetic algorithm to control springback of stamping parts. An uncertain optimization method was suggested in [19] to obtain the optimal variable binder force in $U$ shaped forming. The finite element method was employed to simulate the forming process, and an uncertain objective function representing the springback magnitude was created. A hybrid optimization algorithm based on the intergeneration projection genetic algorithm and neural network was used to obtain the optimum. A model of stamping part was developed in [20] through finite element simulation codes and validated by experimental methods. The search for optimal tool configurations was performed by optimizing a desirability function and by means of a genetic algorithm based on an optimization code. The method was applied on a $U$ shape part. The artificial neural networks were used in [21] to predict the punch radius based on the results of air-bending experiments of sheet metals. A genetic algorithm was used to optimize the weights of neural network and then, with the predicted punch radius and other geometrical parameters of a tool, 2D and 3D ABAQUS finite-element models were established. In paper [22] the authors investigated the effect of the number of input parameters and the size of training data sets on the predictive capability of a neural-network-based control system for springback prediction in air bending.

This paper is focused on the prediction of the springback in the free cylindrical bending process of DQ steel sheet. ANN and ANFIS models were developed for this purpose. Some bending experiments were carried out on DQ steel. These experiments were also simulated using the finite element method. The results of the finite element model were compared with experiments and used as training data for ANN and ANFIS models. The performance of the ANN and ANFIS model in training and testing are compared with those of the FEM using statistic criteria. 


\section{Experimental procedure}

The experimental tests were performed on rectangular samples with dimensions of $25 \times 10 \mathrm{~mm}$ cut from DQ steel sheet with thickness of $0.5 \mathrm{~mm}$. These sheet metals were bent on a free cylindrical bending device with 7 different radii (Fig. 1) of the active elements 10,15,20,25,30,35,40 $\mathrm{mm}$. Each radius following the extraction of the bent part from the bending die was measured. Five bending experiments were repeated for each determination and an average of that five individual values was calculated. The tests were performed at a constant velocity. The measurement results were used to determine the springback coefficient.

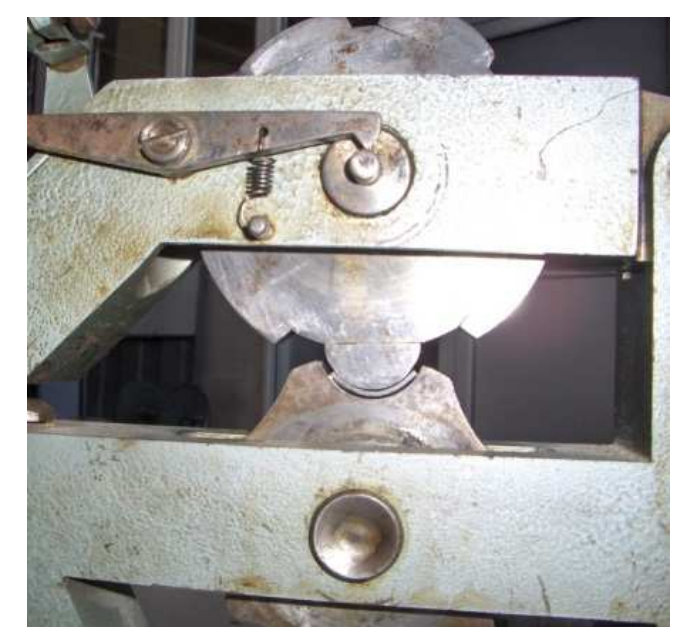

Fig. 1 Set-up of the bending device

The accuracy of the part after bending was defined using the springback coefficient $\mathrm{K}$ calculated according to Eq.(1) found in reference [23].

$$
\beta=\frac{R_{1}+T / 2}{R+T / 2}
$$

where: $R$ is part radius, $R_{l}$ is die radius and $T$ represents the thickness of the material.

\section{Finite element simulation of the free cylindrical bending process}

In order to obtain sufficient input-output data sets for training and testing, the free cylindrical bending process was simulated using the finite element method. Simulation tests were performed with the program ABAQUS/Standard. The finite element simulation was carried out for various sets of parameters. The variable parameters used for the simulation of the bending process are given below:

- sheet thickness $t=0.5 ; 0.8 ; 1.2 ; 1.5 ; 2 \mathrm{~mm}$;

- punch radius $r_{p}=10 ; 15 ; 20 ; 25 ; 30 ; 35 ; 40 \mathrm{~mm}$;

- friction coefficient $\mu=0.06 ; 0.125 ; 0.2$.

All numerical have been performed keeping constant:

- the length (L);

- width of the raw part;

- bending distance.

A Swift hardening law has been adopted:

$$
\sigma_{c}=K\left(\varepsilon_{0}+\varepsilon_{p}\right)^{n}
$$

The coefficients of the hardening law corresponding to the DQ steel sheet $(0.5 \mathrm{~mm}$ nominal thickness) are given in Table 1. 
Table 1 Mechanical parameters determined by uniaxial tensile tests

\begin{tabular}{|l|l|}
\hline Denomination & Experimental value \\
\hline Young's modulus & $\mathrm{E}=2,1 * 10^{5}\left[\mathrm{~N} / \mathrm{mm}^{2}\right]$ \\
\hline Poisson's ratio & $\mathrm{v}=0,3$ \\
\hline Coefficients of Swift's & $\mathrm{K}=532\left[\mathrm{~N} / \mathrm{mm}^{2}\right]$ \\
hardening law (see Eq.(2)) & $\varepsilon_{0}=0.00778$ \\
& $\mathrm{n}=0,258$ \\
\hline
\end{tabular}

The finite element mesh used to discretize the raw part had: 26 equidistant nodes and 25 finite elements B21 (Beam elements with two nodes). The blank and the tools geometry are axisymmetric. The active areas of tools (punch, die) are defined in an analytical manner. The positions of these tools are controlled by two nodes of reference. The type of contact between the raw part and tools is the Coulomb, friction coefficient being the same for both punch and die.

The ABAQUS model consists in two steps:

- first step: descending motion of the punch;

- second step: simulation of the springback process following the extraction of the bent part from the bending die. In the second stage of the simulation, the active surfaces of the tools are removed and the specimen is allowed to relax.

The methodology consisted in repeating the simulation of the free cylindrical bending processes, covering a range of values representative for each of the above-mentioned parameters. Therefore the data sets obtained by experimental procedure were significantly increased. The result of the FE simulation is the springback coefficient as a function of the bending parameters.

Figure 2 shows the part profile before and after the extraction from the bending die as predicted by numerical simulation with ABAQUS.

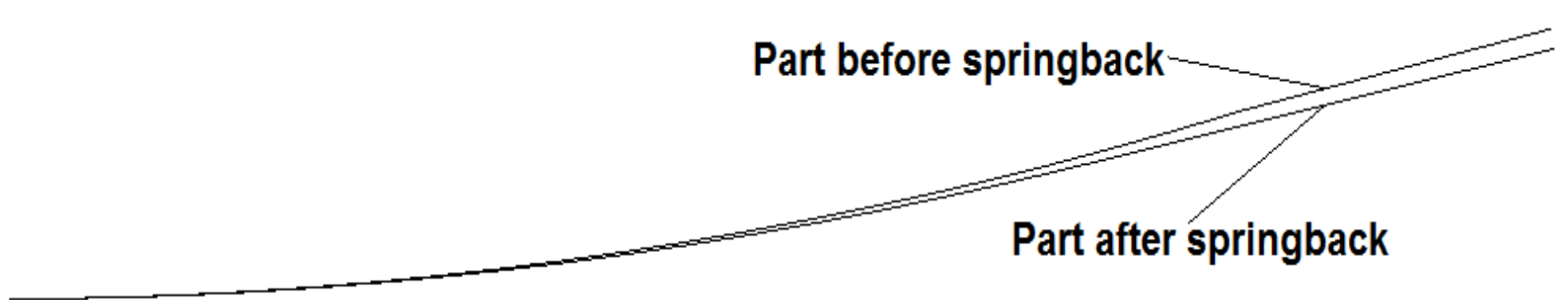

Fig.2. Graphical representation of the springback phenomenon

The accuracy of the developed finite element model was evaluated by the relative error (RE) and mean relative error (MRE) calculated as follows:

$$
\begin{aligned}
& R E(\%)=\left|\frac{p_{i}-a_{i}}{a_{i}}\right| \times 100 \\
& \operatorname{MRE}(\%)=\frac{1}{N} \sum_{i=1}^{N}\left|\frac{p_{i}-a_{i}}{a_{i}}\right| \times 100
\end{aligned}
$$

where: $a$ is the actual value from experiments, $p$ is the predicted value by models and $N$ is the number of patterns.

The obtained mean relative errors were less than $1.3 \%$, confirming the validity of the simulations.

A graphical comparison between the obtained results by FEM with experimental data is shown in Fig. 3. 


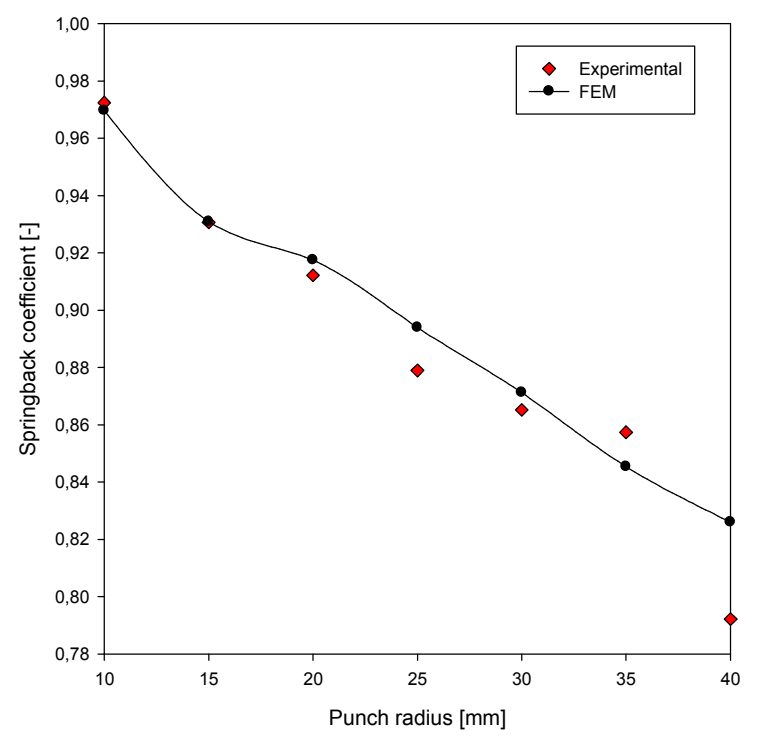

Fig.3 Springback coefficient obtained by FEM and experiments

It can be noticed that the results obtained by numerical simulation are closed to the experiments. Therefore the numerical results obtained from finite element simulation can be used for training and testing the ANN and ANFIS models.

\section{Artificial neural networks modeling}

In this paper, a feed-forward neural network with back propagation algorithm was developed to predict the springback coefficient. In order to obtain the optimum architecture of the network, several ANN architectures were investigated considering different number of hidden layers, neurons in the hidden layer and transfer functions. The trials showed that the best network architecture for springback prediction problem consists of one input layer having three neurons, one hidden layer with six neurons and an output layer with one neuron. The network architecture is shown in Fig. 4. The input parameters were chosen as sheet thickness, punch radius, friction coefficient, while the output parameter is the springback coefficient directly imposed by the application.

The neural network was trained using the Levenberg - Marquardt back-propagation algorithm. A number of 107 data sets were used in the training phase, 19 data sets to validate the ANN model produced in the training phase and 19 data sets to perform the testing of the network. The change of the mean squared error for all phases is shown in Fig.5.

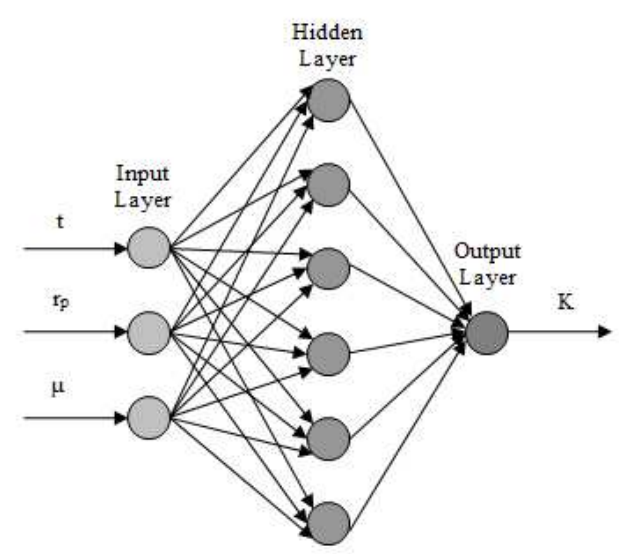

Fig. 4 ANN model for springback prediction

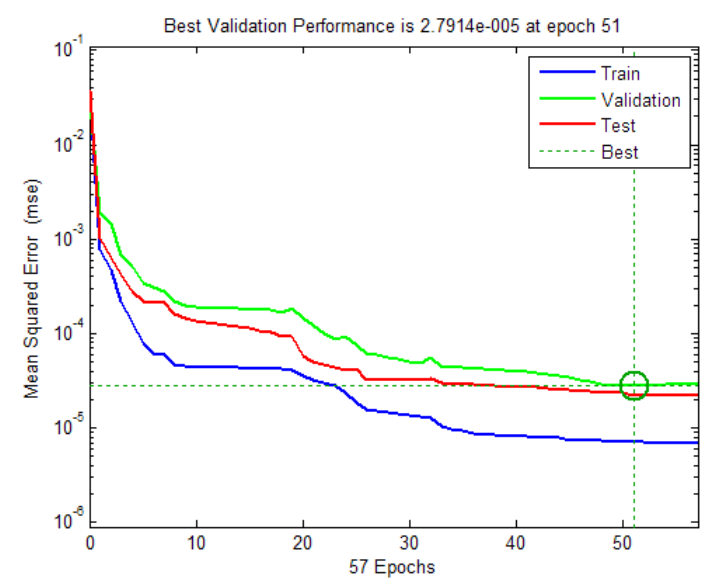

Fig.5 Mean squared error for ANN model

The expected value of the error performance of the network has been reached after 51 iterations. 


\section{ANFIS modeling}

The Adaptive Neuro-Fuzzy Inference System (ANFIS) is a hybrid system which combines the learning capabilities of a neural network and fuzzy logic reasoning concepts. This model was proposed by Jang [24] being used by researchers for modelling and prediction in various engineering systems.

The architecture of the ANFIS system consists of five layers, namely, the fuzzy layer, product layer, normalized layer, de-fuzzy layer and total output layer. A detailed description of the ANFIS system can be found in $[24,25]$.

The ANFIS model for springback coefficient prediction was developed using MATLAB Fuzzy Logic Toolbox (2010). The architecture of the ANFIS model used in this study is based on firstorder Takagi-Sugeno [26] model and has three inputs (sheet thickness, punch radius, friction coefficient) and an output representing the springback coefficient as shown in Fig. 6.

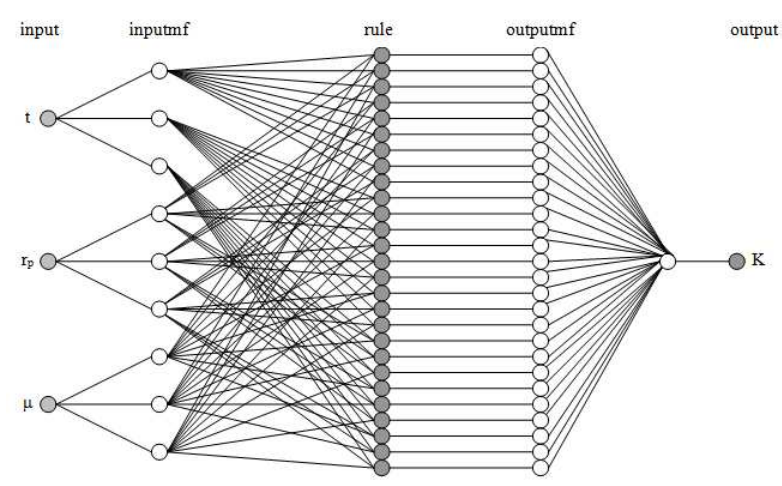

Fig. 6 Developed ANFIS model for springback prediction

The range of input parameters was: $0.5 \leq t \leq 2 \mathrm{~mm} ; 10 \leq r_{p} \leq 40 \mathrm{~mm}$ and $0.06 \leq \mu \leq 0.2$.

A set of 107 data items for training and 19 input-output pairs both for validation and testing, were used. After experimenting different learning algorithms with different epochs and different membership functions for every input parameter the best correlation was found using hybrid (back propagation and least squared error) learning algorithm, 100 epoch and „trimf” membership function for all input parameters.

The relationship between input and output parameters was defined in this ANFIS model by 27 rules. The rule viewer of springback coefficient (Fig.7) depicts all parts of the fuzzy inference process from inputs to outputs. Each column of the plot corresponds to an input variable while the row corresponds to one rule.

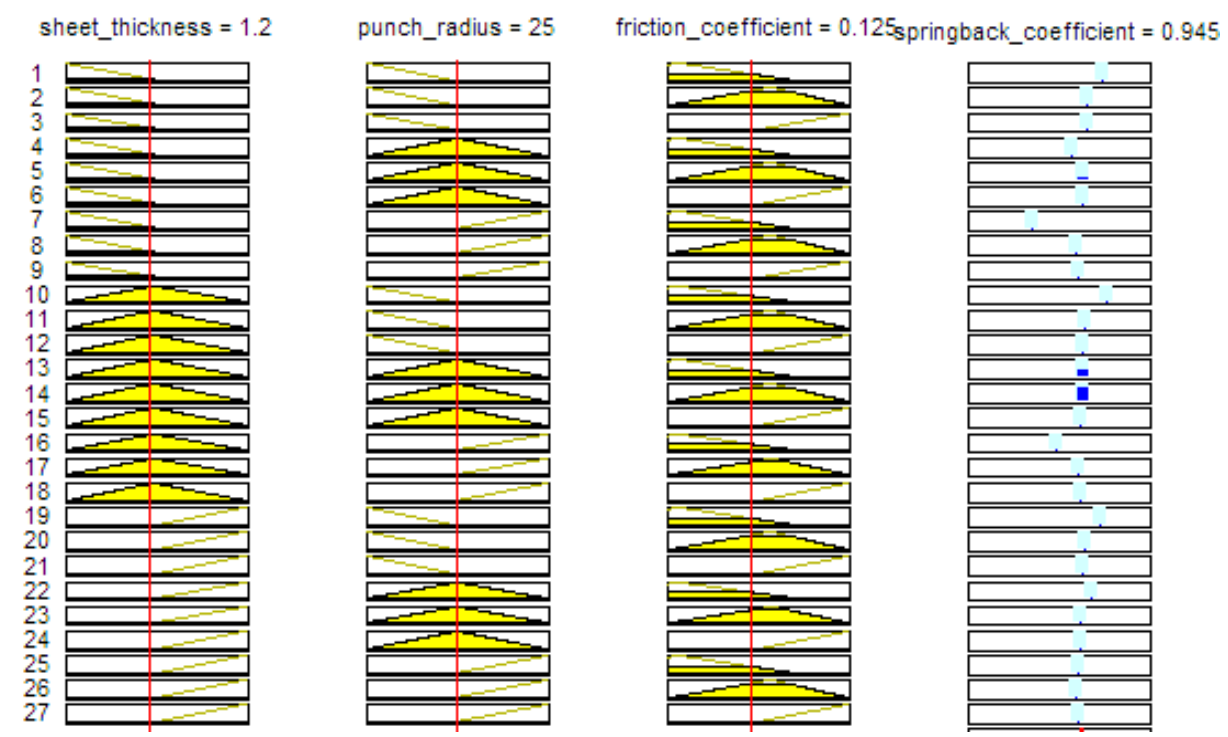

Fig. 7 Rule viewer for springback coefficient 


\section{Results and discussions}

The accuracy of the developed ANN and ANFIS models was evaluated by considering the Root Mean Square Error (RMSE) Eq. (5), correlation coefficient (R) Eq. (6) and Mean Relative Error (MRE) Eq. (4).

$$
\begin{aligned}
& R M S E=\sqrt{\frac{1}{N} \times \sum_{i=1}^{N}\left(a_{i}-p_{i}\right)^{2}} \\
& R=\frac{n \sum a p-\left(\sum a\right)\left(\sum p\right)}{\sqrt{n\left(\sum a^{2}\right)-\left(\sum a\right)^{2}} \sqrt{n\left(\sum p^{2}\right)-\left(\sum p\right)^{2}}}
\end{aligned}
$$

where: $a$ is the actual value from experiments, $p$ is the predicted value by models and $N$ is the number of patterns.

Table 2 shows the results of the ANN and ANFIS models measured by the RMSE, $\mathrm{R}^{2}$ and MRE. It can be seen that the coefficient of determination $\mathrm{R}^{2}$ values in the training set were 0.9942 in case of the ANN model and 0,9996 in case of the ANFIS model. The $\mathrm{R}^{2}$ values in the testing set were 0.9914 in case of the ANN model and 0.9367 in case of the ANFIS model. This means that the regression line fits well the data, $\mathrm{R}^{2}$ values being closer to $1 .\left(\mathrm{R}^{2}=1\right.$ means perfect fit $)$. The values of RMSE in the training set are 0.0057 for ANN model and 0.0016 for ANFIS respectively 0.0047 for ANN model and 0.01 for ANFIS in the testing set. The MRE values are less than $1 \%$ in all cases indicating that the ANN and ANFIS models perform better in predicting the springback coefficient.

Table 2 Comparison of performance of the models used on the basis of statistical criteria

\begin{tabular}{|c|c|c|c|c|c|c|}
\hline \multirow{2}{*}{ Model } & \multicolumn{3}{|c|}{ Training set } & \multicolumn{3}{c|}{ Testing set } \\
\cline { 2 - 7 } & RMSE & $\mathrm{R}^{2}$ & MRE[\%] & RMSE & $\mathrm{R}^{2}$ & MRE[\%] \\
\hline ANN & 0.0057 & 0.9942 & 0.8862 & 0.0047 & 0.9914 & 0.3644 \\
\hline ANFIS & 0.0016 & 0.9996 & 0.2657 & 0.01 & 0.9367 & 0.6135 \\
\hline
\end{tabular}

Fig. 8 (a-d) shows the performance of both models in comparison with actual values (FEM) for both training and testing sets. It can be seen that the proposed ANN and ANFIS models could learn the relationship between different input-output data sets, the correlation coefficient $\mathrm{R}$ being very close to 1 ( $\mathrm{R}=1$ means close relationship).
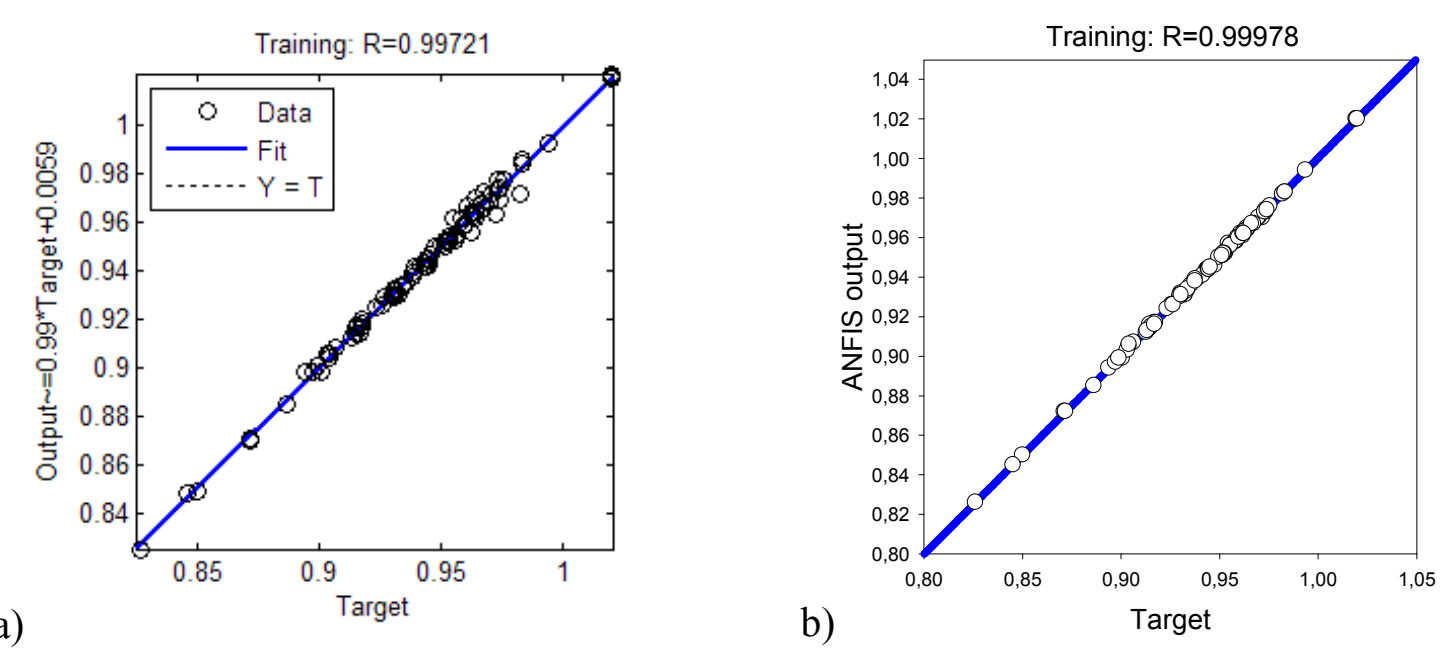

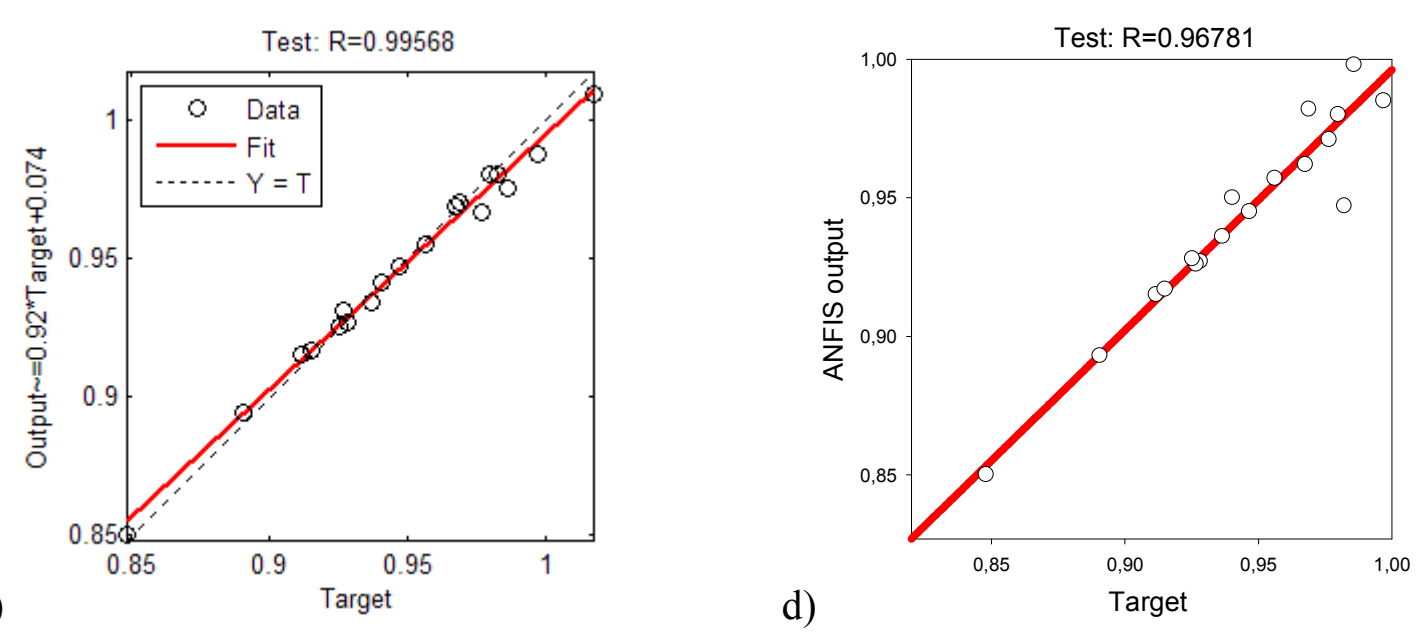

Fig. 8 Comparison of actual springback coefficient values with the predicted values:

a) training stage of ANN b) training stage of ANFIS, c) testing stage of ANN d) testing stage of ANFIS.

A graphical comparison between the ANN, ANFIS models and the actual results is shown in Fig. 9. It can be noticed that the ANN and ANFIS results are very closed to the results obtained by FEM, the models were able to fit most of the springback coefficient values close to the targets. This shows the ability of the developed models to predict the springback in the free cylindrical bending process of DQ steel sheets.

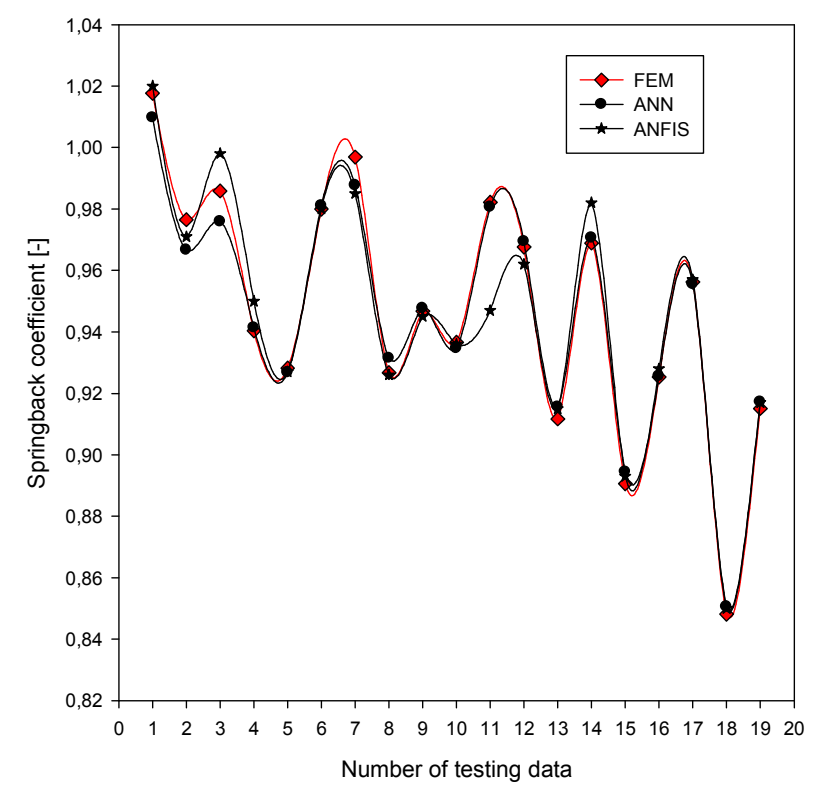

Fig. 9 Comparison of the obtained results by the ANN and ANFIS models with FEM for springback coefficient

Judging against the free statistical criteria RMSE, $\mathrm{R}^{2}$ and MRE in the testing set the ANN model perform better than ANFIS model in predicting the springback coefficient of the metallic sheets subjected to free cylindrical process. However both models are able to provide predictions of the springback coefficient closed to that of finite element method.

\section{Summary}

The use of the ANN and ANFIS modeling technique was assessed to see whether the constructed models can be used for predicting the springback coefficient of DQ steel sheets subjected to free cylindrical bending process. For this purpose, experimental tests of free cylindrical bending were 
performed under different operating conditions to obtain input-output data sets. In order to enrich the experimental data set, finite element simulation was carried out. Then, an ANN and ANFIS models for springback prediction were developed. The prediction performance of the developed ANN and ANFIS models was measured using the root mean square error, coefficient of determination and mean relative error. The ANN and ANFIS models reveal a good statistical performance with the RMSE in the range of $0.0047-0.01$, MRE in the range of $0.36-0.61 \%$, correlation coefficients in the range of $0.9678-0.9957$.

The results show that the springback in the free cylindrical bending process can be modeled accurately using the ANN and ANFIS approach. These new techniques are faster than the finite element method and require only a limited number of tests instead of an experimental study. The use of these techniques in bending processes can save both time and funds.

\section{Acknowledgment}

This paper was supported by the project "Development and support of multidisciplinary postdoctoral programmes in major technical areas of national strategy of Research - Development Innovation" 4D-POSTDOC, contract no. POSDRU/89/1.5/S/52603, project co-funded by the European Social Fund through Sectoral Operational Programme Human Resources Development 2007-2013."

\section{References}

[1] I.A. Burchitz, Improvement of Springback Prediction in Sheet Metal Forming, Ph.D thesis, Rotterdam, 2008, pp. 19.

[2] M. Samuel, Experimental and numerical prediction of springback and side wall curl in U-bendings of anisotropic sheet metals, Journal of Materials Processing Technology 105 (2000) 382-393.

[3] C. Gomes, O. Onipede, M. Lovell, Investigation of springback in high strength anisotropic steels, Journal of Materials Processing Technology 159 (2005) 91-98.

[4] Y.H. Moon, S.S Kang, J.R Cho, T.G Kim, Effect of tool temperature on the reduction of the springback of aluminum sheets, Journal of Materials Processing Technology 132 (2003) 365-368.

[5] M.L. Garcia-Romeu, J. Ciurana, I. Ferrer, Springback determination of sheet metals in an air bending process based on an experimental work, Journal of Materials Processing Technology 191 (2007) 174-177.

[6] J.R. Cho, S.J. Moon, Y.H. Moon, S.S. Kang, Finite element investigation on springback characteristics in sheet metal U-bending process, Journal of Materials Processing Technology 141(1) (2003) 109-116.

[7] T. Hama, T. Nagata, C. Teodosiu, A. Makinouchi, H. Takuda, Finite-element simulation of springback in sheet metal forming using local interpolation for tool surfaces, International Journal of Mechanical Sciences 50 (2008) 175-192.

[8] S.K. Panthi, N. Ramakrishnan, M. Ahmed, S.S. Singh, M.D. Goel, Finite Element Analysis of sheet metal bending process to predict the springback, Materials and Design 31 (2010) 657-662.

[9] L.P. Lei, S.M. Hwang, B.S. Kang, Finite element analysis and design in stainless steel sheet forming and its experimental comparison, Journal of Materials Processing Technology 110 (2001) $70-77$.

[10] K. Yilamu, R. Hino, H. Hamasaki, F. Yoshida, Air bending and springback of stainless steel clad aluminum sheet, Journal of Materials Processing Technology 210 (2010) 272-278. 
[11] D. Zhang, Z. Cui, X. Ruan, Y. Li, An analytical model for predicting springback and side wall curl of sheet after U-bending, Computational Materials Science 38(4) (2007) 707-715.

[12] H. Liu, Z. Xing, Z. Sun, J. Bao, Adaptive multiple scale meshless simulation on springback analysis in sheet metal forming, Engineering Analysis with Boundary Elements 35 (2011) 436-451.

[13] X. Li, Y. Yang, Y. Wang, J. Bao, S.P. Li, Effect of the material hardening mode on the springback simulation accuracy of V-free bending, Journal of Materials Processing Technology 123 (2002) 209-211.

[14] S. Chatti, N. Hermi, The effect of non-linear recovery on springback prediction, Computers and Structures 89 (2011) 1367-1377.

[15] H. Baseri, M. Bakhshi-Jooybari, B. Rahmani, Modeling of Spring-back in V-die Bending Process by Using Fuzzy Learning Back-propagation Algorithm, Expert Systems with Applications 38 (2011) 8894-8900.

[16] V. Nasrollahi, B. Arezoo, Prediction of springback in sheet metal components with holes on the bending area, using experiments, finite element and neural networks, Materials and Design 36 (2012) 331-336.

[17] W. Liu, Q. Liu, F. Ruan, Z. Liang, H. Qiu, Springback prediction for sheet metal forming based on GA-ANN technology, Journal of Materials Processing Technology 187-188 (2007) 227-231.

[18] L. Wei, Y. Yuying, X. Zhongwen, Z. Lihong, Springback control of sheet metal forming based on the response-surface method and multi-objective genetic algorithm, Materials Science and Engineering A 499 (2009) 325-328.

[19] C. Jiang, X. Han, G.R. Liu, G.Y. Li, The optimization of the variable binder force in U-shaped forming with uncertain friction coefficient, Journal of Materials Processing Technology 182 (2007) 262-267.

[20] Y. Ledoux, P. Sébastian, S. Samper, Optimization method for stamping tools under reliability constraints using genetic algorithms and finite element simulations, Journal of Materials Processing Technology 210 (2010) 474-486.

[21] Z. Fu, J. Mo, L. Chen, W. Chen, Using genetic algorithm-back propagation neural network prediction and finite-element model simulation to optimize the process of multiple-step incremental air-bending forming of sheet metal, Materials and Design 31 (2010) 267-277.

[22] A. Forcellese, F. Gabriella, Artificial neural-network-based control system for springback compensation press-brake forming, International Journal of Materials and Production Technology 16 (2001) 545-563.

[23] D.A. Smith, Die Design Handbook, third ed., Society of Manufacturing Engineers, 1996.

[24] J.S.R. Jang, Anfis: adaptive-network-based fuzzy inference system, IEEE Transactions on Systems, Man, and Cybernetics 23 (1993) 665-685.

[25] J.S.R. Jang, C.T. Sun, E. Mizutani, Neuro-Fuzzy and Soft Computing, Prentice-Hall, 1997, pp. 614.

[26] T. Takagi, M. Sugeno, Derivation of fuzzy control rules from human operator's control actions, Proceedings of the IFAC Symposium on Fuzzy Information, Knowledge Representation and Decision Analysis (1983) 55-60. 